\title{
Research on the Invulnerability of Chinese Banking System
}

\section{Hengguo Luo}

Business School, China University of Political Science and Law, Beijing, China

\section{Email address:}

15559818968@163.com

\section{To cite this article:}

Hengguo Luo. Research on the Invulnerability of Chinese Banking System. International Journal of Economics, Finance and Management Sciences. Vol. 9, No. 3, 2021, pp. 112-118. doi: 10.11648/j.ijefm.20210903.13

Received: April 21, 2021; Accepted: June 4, 2021; Published: June 10, 2021

\begin{abstract}
Based on the stock transaction data of China's listed banks from 2007 to 2020, this paper constructs the complete network of tail risk spillovers among banks using the Least Absolute Shrinkage and Selection Operator (LASSO) quantile regression, and dynamically examines the characteristics of the network topology and the survivability of China's banking system. The results show that the newly listed banks are mainly the risk bearers. The role of a single bank as an isolator, risk bearer and risk disseminator in the network will change over time. City commercial banks have gradually changed from the role of risk bearer to both risk bearer and risk disseminator. The attack experiments on the Bank of China, China Merchants Bank, China CITIC Bank and Zhengzhou Bank those have the largest number of weighted media in the network for the networks of 2016, 2018, 2019 and 2020, show that large-scale cascading failure can occur in the network by changing the parameters. If the attacked bank is a risk communicator, a larger cascading effect may occur, in turn, lead to the Invulnerability of the whole network reduced. In addition, we find that the scale of network cascading failure is related to the type of attacked bank and the characteristics of its adjacent banks: if the neighbor bank is the risk bearer, the risk will not be passed down; If its adjacent banks are risk dispersers, the risks will be further spread and expanded, that is, the scale of cascade failure depends on the cluster structure of the network.
\end{abstract}

Keywords: Risk Spillover Network, Topology Analysis, Risk Contagion, Invulnerability

\section{Introduction}

Preventing and defusing financial risks, especially preventing systemic financial risks, is the fundamental task of financial area. With the development of China's financial industry, financial companies have not only establish complicated relationships through such transactions as payment and settlement, acceptance bill, inter-bank lending, discount and so on, but also through the rapid development of derivative products under the impact of the wave of financial innovation. Traditional economics is weak in analyzing this complex relationship and the path of risk transmission. However, due to the isomorphism of complex network and financial system in the formation, many characteristics of systemic financial risk are corresponded to the characteristics of complex network. With the help of complex network, it can vividly and accurately describe the intricate relations between the main companies of the system. Moreover, it can analyze the diffusion path and diffusion trend of financial system risks [1]. Therefore, applying complex network to study systemic risk has become a new research hotspot in recent years.

The complex network of financial system constructed by existing literatures can be divided into three categories according to the different methods to calculate the connection coefficients between nodes: (1) Mean spillover network, which uses Granger causality test to determine the connection relationship between nodes. Proposed by Billio et al. [2] However, since the return of asset in the financial market has a characteristic of fluctuation clustering, does not comply with the normal distribution and has an obvious peak and fat tails, there is a certain error in the connection relationship between nodes determined by Granger causality test [3]. (2) Volatility overflow network, its core idea is to use Vector Autoregressive model (VAR) model to build coefficient matrix, and then use generalized variance decomposition technology to decomposed covariance to determine correlation index matrix, the connection edges and weights [4]. However, the vector autoregressive model has a large number of parameters to be estimated and tedious calculation. Therefore, this method is not suitable for the financial system with a large number of nodes [5]. (3) Risk spillover network, the tail risk of financial 
companies are measured by applying the conditional value-at Risk (VaR), and quantile regression technology is applied to detect the intercorrelation and the strength of the connection between companies [6-7]. This method has been recognized and accepted by most scholars because of its wide practicability.

Hautsch et al. [6] constructed a risk spillover network by the interdependence between firms' tail risk exposures of more than 100 financial firms of the United States, and found that risk contagion among financial firms was the main cause of market systemic risks. Nguyen et al. [8] map the entire network of tail risk dependence among 21 major cryptocurrencies and find that Bitcoin and Litecoin are the major drivers of tail risk when markets are bullish, and Ethereum and Ethereum Classic are major drivers of tail risk when markets are bearish. Li et al. [9] use the sample of 19 international financial markets to analyze the tail risk contagion between international financial market during the COVID-19 epidemic. And find that the COVID-19 epidemic increases the number of contagion channels in the international financial system. The clustering level of the financial system has a significant growth during the COVID-19 pandemic, and the number of risk drivers is also larger than risk takers. Javed et al. [10] investigated the spillover risk and systemic risk of the troubled banking sectors of the five countries- Greece, Ireland, Italy, Portugal and Spain, for the rest of the European and the US banking sector using the conditional value-at-risk framework. And find the magnitude of these risks, originating from the five countries, is large. These risks affect banking of large European and the US banking sectors more than the rest.

Jiang and Zhang [3] constructed the risk spillover network of China's listed banks, and found that tail risk spillover would reduce the risk level of the banks themselves, but enhance the interconnectedness of the bank network and increase the systemic risk of the network as a whole. In addition, the large state-owned banks play a central role in the banking network and have strong tail risk spillover effect. $\mathrm{Xu}$ [11] studied the important institutions in China's banking and securities system by using risk spillover network, and verified that the important firms are time-varying. Li et al. [12] built a risk spillover network to measure the network connectivity of China's listed financial firms in terms of the three levels of system, department and institution, and found that the system connectivity had periodic characteristics. The level of connectivity reached the peak in the stage of risk accumulation and would gradually fall after risk release. Large commercial banks contributed the most to the systemic risk, and insurance companies gradually became systemically important institutions.

Although risk spillover network has been paid close attention and recognized by scholars to investigate risk contagiousness among financial company and assess systemic risk. However, the existing research, especially on the research of China's financial systemic risk, is still very inadequate in following aspects: First, most domestic scholars focus on the correlation analysis among financial firms, and seldom evaluate the dynamic change process of network structure. Second, most of the studies only evaluate the contribution of a single financial firm to the system risk, and few evaluate the invulnerability and survivability of the overall network. Invulnerability refers to the ability of the network to accept risks and maintain the stability of the financial system under the impulse of the failure event or external stress. Testing the invulnerability of a network, on the one hand, can provide a measure of the size of the systemic risk, on the other hand, by identifying the key nodes that can cause large-scale cascading failures of the network can guide regulators to formulate strategies. So, this paper aims to constructs a network of listed banks and measures the invulnerability of China's banking system based on financial market data, so as to provide scientific guidance for preventing financial systemic risks, maintaining financial security and stability and establishing macro-prudential policies in China.

The remaining sections of this paper are as follows. In Section 2, we introduce all technical methods used in this paper, including the calculation of the network connection coefficient and invulnerability, and the fitting technique. In Section 3, we present the network construction of Chinese banking system. Section 4 we present our analysis of the invulnerability of Chinese banking system and results. In Section 5 we present our conclusions and final remarks.

\section{Method}

\subsection{To Determine the Network Connection Coefficient}

To construct the risk spillover network, it is necessary to determine the connection edge between nodes in the network, including the direction and weight of the connection edge. We use LASSO regression to determine the risk drivers that significantly affect the banking institution $\mathrm{i}$, and then perform quantile regression on the identified risk drivers, and the estimated parameter $\theta$ value is the risk spillover coefficient.

The value of the conditional $\operatorname{VaR}_{q}^{i}$ of firm i at $\mathrm{t}=1, \ldots \mathrm{T}$ is expressed by a linear function of specific tail risk drivers of $i$ :

$$
\operatorname{VaR}_{q}^{i}=W^{(i)^{\prime}} \xi_{q}^{i}
$$

The vector $W^{(i)^{\prime}}$ and $\xi_{q}^{i}$ in the formula respectively denote the risk drivers of firm $i$ and its corresponding regression coefficient.

$\operatorname{VaR}_{q, t}^{i}=\left(\operatorname{VaR}_{q, t}^{i} \mid W_{t}^{(i)}\right)=-Q_{q, t}^{i}$ denotes that the value at risk of firm $i$ is the negative q quantile of asset return at $t$.

The Equation (2) can be expressed by quantile regression model:

$$
X_{t}^{i}=-W^{(i)^{\prime}} \theta_{q}^{i}+\varepsilon_{t}^{i}
$$

Where, $X_{t}^{i}$ stands for the log return of firm i at time t. Given the risk drivers of firm $i$, an estimated value of $\widehat{\theta_{q}^{\imath}}$ can be obtained by minimizing the standard linear quantile regression: 


$$
\frac{1}{T} \sum_{t=1}^{T}\left[q-I\left(X_{t}^{i} \leq W^{(i)^{\prime}} \theta_{q}^{i T}\right)\right]\left(X_{t}^{i}+W^{(i)^{\prime}} \theta_{q}^{i T}\right)
$$

Where, $\mathrm{T}$ is the number of sample observations, $\mathrm{I}(\cdot)$ is the indicator function. When $X_{t}^{i} \leq W^{(i)^{\prime}} \xi_{q}^{i T}$, the indicator function equals 1 , otherwise is $0 . \mathrm{K}$ is the number of repressors of $W^{(i)^{\prime}}$, and $\xi_{k}^{i}$ is the $\mathrm{k}^{\text {th }}$ element of the coefficient vector $\xi^{i}$.

Equation (2) can be expressed by estimated $\widehat{\theta_{q}^{l}}$ as follows:

$$
\widehat{\operatorname{VaR}_{q}^{l}}=W^{(i)^{\prime}} \widehat{\theta}_{q}^{l}
$$

\subsection{To Calculate the Invulnerability of Network}

Under normal circumstances, random failures of a few nodes in the network have little impact on the whole network, while attacks on key nodes may cause risks to be redistributed among the networks, which makes more nodes fail or even the whole network collapse, triggering systemic risks. The initial risk of node $\mathrm{n}$ in the network is defined as:

$$
L_{n}(0)=(1+q) B_{n}^{\alpha}
$$

Where, $\mathrm{q}$ and $\alpha$ are adjustable parameters to control risk distribution, and $\mathrm{q} \geq 0, \alpha \geq 0 ; B_{n}$ is the weighted generalized betweenness of node $n$.

$$
B_{n}=\sum_{i, j} \frac{g_{i n j}}{g_{i j}}
$$

Where, $g_{i j}$ is the total number of shortest paths between node $\mathrm{i}$ and node $\mathrm{j}$, and $g_{i n j}$ is the number of shortest paths through node $n$ between node $i$ and node $j$, where $i \neq j$. This weighted generalized betweenness considers the two endpoints of each shortest path, which avoids the possibility that the intermediate number of some nodes may be equal to zero, thus avoiding the possibility that some nodes may not take risks at all.

From Equation (5), initially each node bears some risk more or less, and the risk at each node is a nonlinear function of the generalized betweenness, unless the parameter $\alpha$ is equal to 1 . Since the initial risk of a node is formed after a long period of evolution, it is speculated that the risk capacity of a node $C_{n}$ is proportional to its initial risk $L_{n}(0)$, we have:

$$
C_{n}=(1+\beta) L_{n}(0)
$$

Where, $\beta$ is the risk tolerance parameter, let $\beta>0$ to ensure that there will no node produce risk spillover effect at first. $\beta$ is related to the network cost. The larger the $\beta$ is, the greater the risk capacity of the nodes is, indicating that it has a stronger ability to resist the risk spillover, but the higher the cost of network construction. Therefore, the value of $\beta$ should be a trade-off between the network's invulnerability and the construction cost.

If node $\mathrm{N}$ fails, its initial risk will be distributed to other nodes in the network. Considering that the initial risk reallocation is a transient behavior, the risk reallocation of the failure node must pass through its neighboring nodes, so the neighbors of the failure node are most affected. Therefore, we adopt the local allocation strategy, there exist two cases:
First, when node $\mathrm{n}$ fails, if real-time risk information of its neighboring nodes cannot be obtained, it is reasonable to allocate more risks to nodes with larger risk capacity. In this situation, the risk ratio $\Pi_{e}^{(1)}$ that adjacent node e receives from the failure node $\mathrm{n}$ is:

$$
\Pi_{e}^{(1)}=\frac{c_{e}}{\sum_{i \in Y_{n} C_{i}}}
$$

Where, $\mathrm{e}$ is an adjacent node of the fault node $\mathrm{n} ; \Upsilon_{n}$ is the set of adjacent nodes of node $\mathrm{n} ; C_{e}$ represents the risk capacity of node e. Secondly, when the real-time risk information of the neighboring nodes is available, we can allocate more risks to the neighboring nodes e and denote the residual risk capacity with $\left(C_{e}-L_{e}\right)$. Therefore, the risk proportion received by the neighboring node e from the failure node $\mathrm{n}$ is:

$$
\Pi_{e}^{(2)}=\frac{C_{e}-L_{e}}{\sum_{i \in Y_{n}}\left(C_{i}-L_{i}\right)}
$$

Where $L_{e}$ is the initial risk of node e, and $C_{e}$ is the risk capacity of node $e$.

Due to the fast propagation speed of cascading failures, it is usually difficult to obtain real-time risk information of each node. Therefore, we use Equation (11) to assign the risk of the failure node to its neighbors. Then the risk absorbed by its neighbor node e from the failure node $\Delta L_{e n}$ can be expressed as:

$$
\Delta L_{e n}=\Pi_{e}^{(1)} L_{n}=\frac{c_{e}}{\sum_{i \in Y_{n} C_{i}}} L_{n}
$$

If the total risk borne by node e exceeds its risk capacity, that is, $L_{e}(t)=L_{e}(t-1)+\Delta L_{e n} \geq C_{e}$, the node e will fail and the risk it bears will be transmitted to its neighboring nodes, making the neighboring nodes bear more risks. If the total risk undertaken by its neighboring nodes exceeds its own risk capacity, these risks will further infect other nodes, and accompanied with a continuous increase of the contagion risk in each round, leading to large-scale cascading failures and systemic risks. Assuming that the initial number of nodes in the network is $\mathrm{N}$ and the number of remaining nodes in the network after node failure is $N^{\prime}$, we use an exponential SCF to measure the survivability of cascading failures:

$$
S C F=\frac{N^{\prime}}{N}
$$

The larger the SCF value, the higher the invulnerability of the network is.

\section{The Network Construction of Chinese Banking System}

In consideration of the availability of data and the changes of the number of listed banks in China, we select the representative listed banks data in 2007, 2010, 2016, 2018, 2019 and 2020 to build the network. Data mainly from the official website of CSI (www.csindex.com.cn). By calculating the basic logarithmic rate of return, we regress the 
equations (2) to get the risk spillover coefficient and risk contagion direction, and construct the risk spillover network.

The statistically significant and non-negative $\theta^{i}$ format the network connectivity. The tail risk input degree for bank $i$ is the total number banks that transmit tail risk to bank $\mathrm{i}$, and

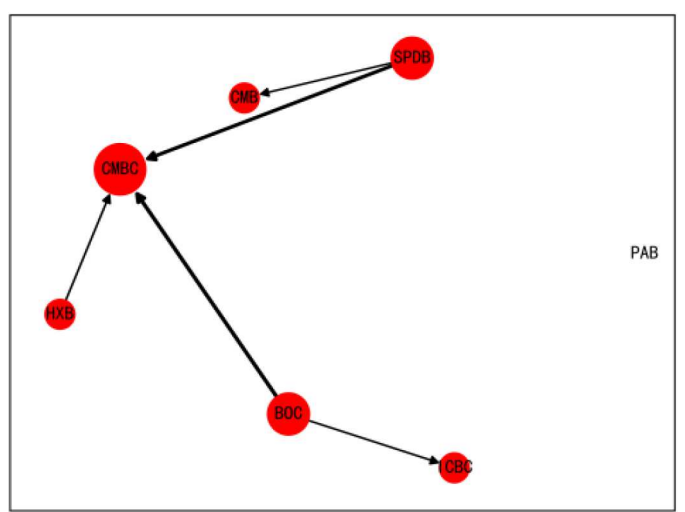

the year 2007

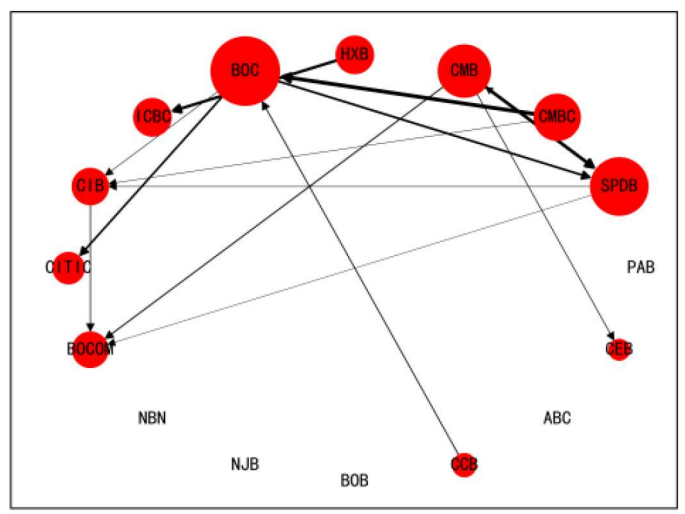

the year 2016

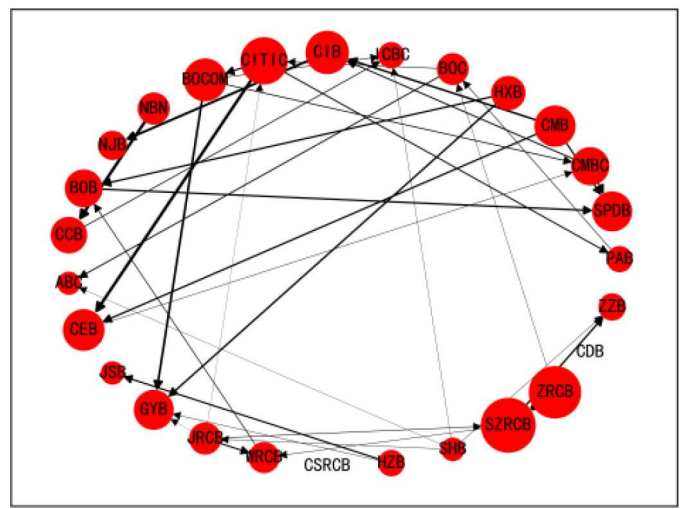

the year 2019 the tail risk output degree for bank $\mathrm{i}$ is the total number of banks that receive the tail risk of bank $i$. The total degree in the entire network is the number of non-zero $\theta$. The risk spillover networks of China's banking system in representative years are shown in Figure 1.

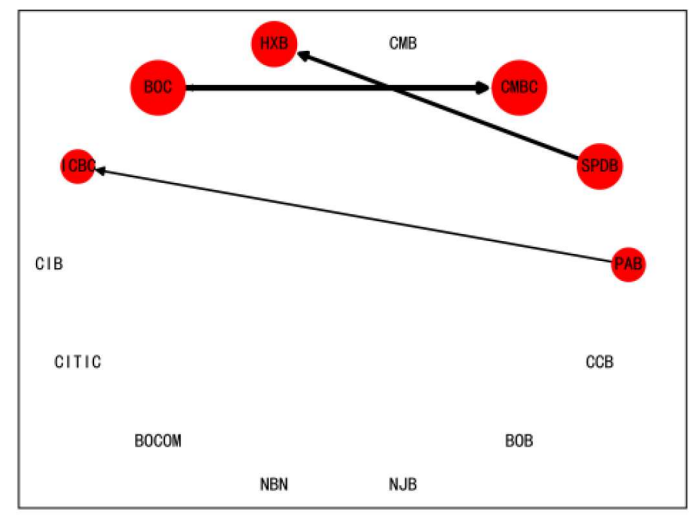

the year 2010

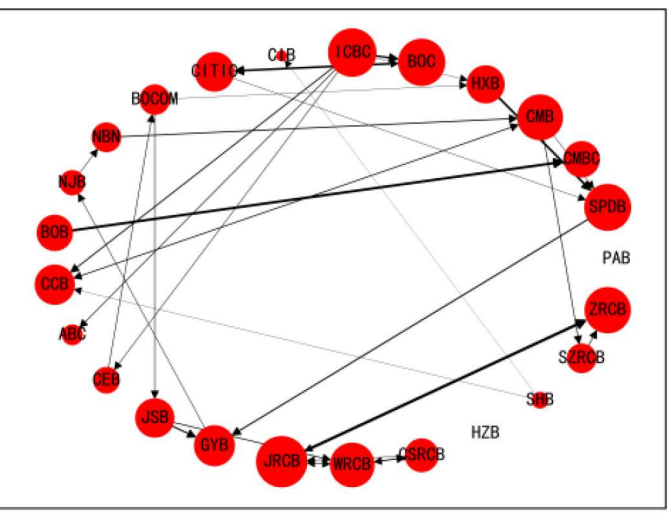

the year 2018

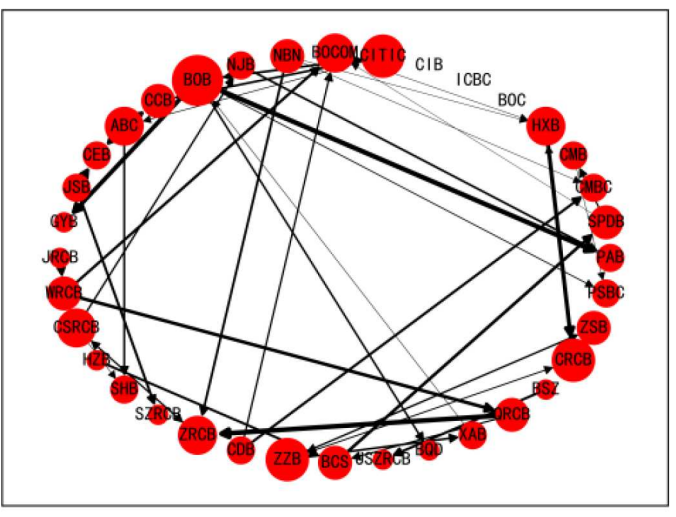

the year 2020

Figure 1. Dynamics of the risk spillover network of China's listed banks.

Note: ABC stands for Agricultural Bank of China; BCS stands for Bank of Changsha; BOB stands for Bank of Beijing; BOC stands for Bank of China; BOCOM stands for Bank of Communications; BQD stands for Bank of Qingdao; BSZ stands for Bank of Suzhou; CCB stands for China Construction Bank; CDB stands for Bank of Chengdu; CEB stands for China Everbright Bank; CIB stands for Industrial Bank; CITIC stands for China CITIC Bank; CMB stands for China Merchants Bank; CMBC stands for China Minsheng Banking; CRCB stands for Chongqing Rural Commercial Bank; CSRCB stands for Changshu Rural Commercial Bank; GYB stands for Bank of Guiyang; HXB stands for Hua Xia Bank; HZB stands for Bank of Hangzhou; ICBC stands for Industrial and Commercial Bank of China; JRCB stands for Jiangyin Rural Commercial Bank; JSB stands for Bank of Jiangsu; JSZRCB stands for Jiangsu Zijin Rural Commercial Bank; NBN stands for Bank of Ningbo; NJB stands for Bank of Nanjing; PAB stands for Ping An Bank; PSBC stands for Postal Savings Bank of China; QRCB stands for Qingdao Rural Commercial Bank; SHB stands for Bank of Shanghai; SPDB stands for Shanghai Pudong Development Bank; SZRCB stands for Jiangsu Suzhou Rural Commercial Bank; WRCB stands for Wuxi Rural Commercial Bank; XAB stands for Bank of Xi'an; ZRCB stands for Rural Commercial Bank of Zhangjiagang; ZSB stands for China Zheshang Bank; ZZB stands for Bank of Zhengzhou. 
The size of the node (red color) in Figure 1 represents the degree center value of the node. The larger the node is, the near to the center position of the network, indicating that the node is of more importance in the banking system. The width of the edge denotes the size of the risk spillover coefficient, that is, the wider the edge of $\theta_{i \rightarrow j}$ is, the greater the risk contribution of firm $i$ to firm $j$ is.

Figure 1 shows banks in the networks can be divided into four categories. The first type of banks has only outward arrows. These kind of banks mainly play the role of risk dispersers in the system. The failure of these firms could have repercussions for many others, while they themselves are relatively immune to the woes of others. Such banks should be the subject of close monitoring by regulators.

The second type of bank is the one with only inward arrows as the risk takers in the network. These banks do not have an impact on other banks, but they may be exposed to other banks' troubles, and they should therefore consider such risk spillovers in their internal risk management.

The third type of bank has both inward and outward arrows, so it acts as risk taker and risk disseminator simultaneously. This bank receive spillover risks from other banks and amplify risks in the system by spreading them. They are key systemic actors and should be regulated accordingly.

The fourth type of bank is not related to other banks, and they are neither risk bearers nor risk disseminators. Its own risks will not have spillover effects and affect the normal operation of other banks.

By comparing the networks in Figure 1, it is found that the network becomes more complex with the newly listed banks joining, and the connections among banks become closer over time. Most of the newly listed banks play the role of risk takers at first, such as China Everbright Bank listed in 2016, Zhangjiagang Bank listed in 2018, Chengdu Bank listed in 2019 and Zijin Bank, Qingdao Bank, Chongqing Rural Commercial Bank and Postal Savings Bank those listed in 2020. The risk isolator will gradually become as a role of the risk bearer, risk disseminator or both risk disseminator and risk bearer. For example, China Construction Bank is an isolator in 2010, became a risk disseminator in 2016, a risk bearer in 2018, and both a risk disseminator and risk bearer in 2019.

Figure 1 shows that before 2016, the major risk disseminators were large state-owned holding commercial banks and national joint-stock commercial banks, such as Bank of China, Agricultural Bank of China, China Construction Bank, Shanghai Pudong Development Bank, Huaxia Bank, Minsheng Bank, etc. After 2018, urban commercial banks gradually became risk dispersers, such as Bank of Shanghai, Bank of Ningbo, Bank of Zhangjiagang, Bank of Chengdu, Bank of Jiangsu, Bank of Hangzhou, etc. From the perspective of risk bearers, it is found that the risk bearers have gradually changed from the original state-owned large commercial banks to urban commercial banks. For example, before 2016, Industrial and Commercial Bank of China, Bank of Communications and some national joint-stock commercial banks are the risk bearers. By 2020, the risk bearers are mainly urban commercial banks. Such as Guiyang Bank, Bank of Shanghai, Sunong Bank, Zhangjiagang Bank, Zijin Bank, Qingdao Bank, Suzhou Bank and so on.

\section{The Invulnerability of Chinese Banking System}

Network invulnerability refers to the ability of the network to receive risks and maintain the stability of the financial system when failures of some nodes occur or external shock or pressure occurs. The more invulnerable the network has, the more stable it is. Here we investigate each network invulnerability under two attack strategies - attack the largest weighted betweenness nodes and attack the smallest weighted betweenness nodes, the results are shown in Figure 2.

Table 1 summarizes the results of attacking the banks with maximum and minimum weighted betweenness in different networks.

Table 1. The results of attacking experiments.

\begin{tabular}{lll}
\hline & The bank with largest weighted betweenness & The bank with smallest weighted betweenness \\
\hline Network in 2007 & China Minsheng Bank & Huaxia Bank, Industrial and Commercial Bank of China \\
Network in 2010 & Bank of China, Minsheng Bank & Bank of Beijing, Agricultural Bank of China \\
Network in 2016 & Bank of China & China Everbright Bank \\
Network in 2018 & China Merchants Bank & Minsheng Bank, Bank of Beijing \\
Network in 2019 & China CITIC Bank & Agricultural Bank of China \\
Network in 2020 & Bank of Zhengzhou & Bank of Suzhou \\
\hline
\end{tabular}

Table 1. Continued.

\begin{tabular}{lllllll}
\hline & \multicolumn{2}{l}{ attacking the smallest weighted betweenness nodes } & \multicolumn{2}{l}{ attacking the largest weighted betweenness nodes } \\
\cline { 2 - 5 } & SCF value & The impact of $\boldsymbol{\alpha}$ & The impact of $\boldsymbol{\beta}$ & \multicolumn{2}{l}{ SCF value } & The impact of $\boldsymbol{\alpha}$ \\
\hline Network in 2007 & $=0.86$ & no & no & $=0.86$ & no & no impact of $\boldsymbol{\beta}$ \\
Network in 2010 & $>0.92$ & no & no & $>0.92$ & no \\
Network in 2016 & $=0.94$ & no & $<0.70$ & The threshold $\alpha=0.2$ \\
Network in 2018 & $=0.96$ & no & no & $<0.70$ & The threshold $\alpha=0.2$ \\
Network in 2019 & $=0.96$ & no & no & $<0.70$ & The threshold $\alpha=0.2$ \\
Network in 2020 & $=0.95$ & no & no & $<0.60$ & The threshold $\beta_{0}=0.36$ \\
\hline
\end{tabular}



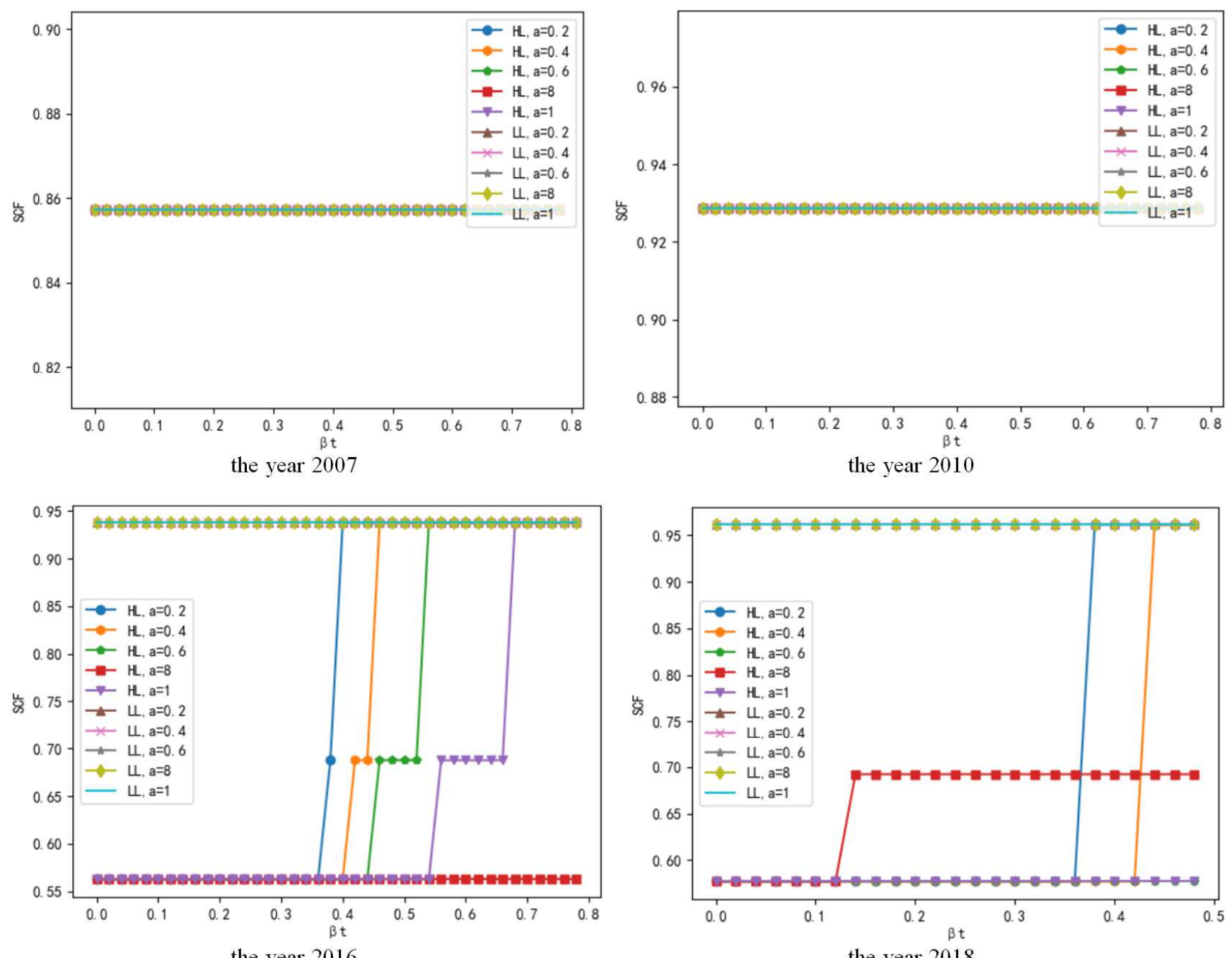

the year 2016
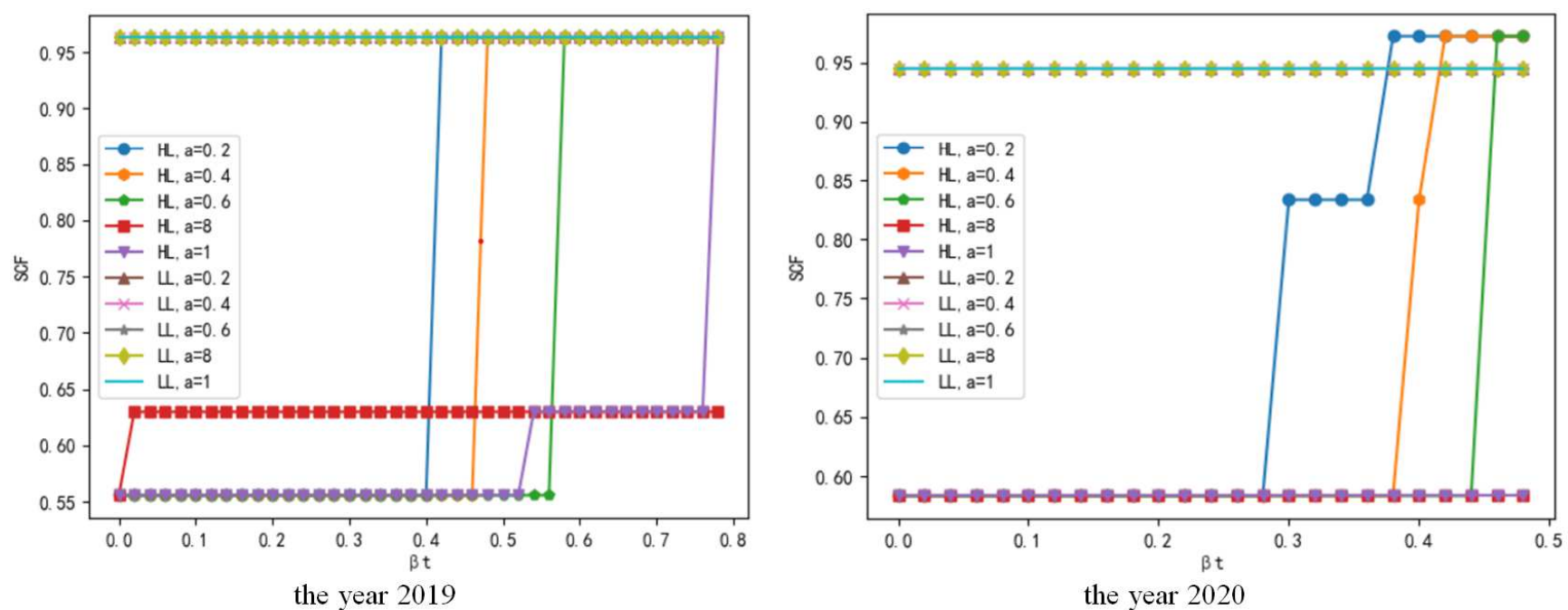

Note: Icon HH represents the node with the largest weighted betweenness; LL represents the node with the smallest weighted intermediate number.

Figure 2. The dynamics of invulnerability of China's bank network.

Table 1 shows that for the network in 2007 and 2010, no matter what the values of $\alpha$ and $\beta$ are, and no matter the attack is on the node with the maximum or minimum weighted betweenness, the SCF values are the same 0.86 and more than
0.92, which means the cascade failure will not occur, that is, the network has good damage resistance.

However, for the banking network in 2016 and later, the SCF value obtained by attacking the node with the maximum 
weighted betweenness is much less than that obtained by attacking the node with the minimum weighted betweenness, indicating that the attack on the node with the maximum weighted betweenness may take the risk of cascading failure. Taking the network in 2020 as an example, the Bank of Zhengzhou has the largest weighted betweenness, and the Bank of Suzhou has the smallest weighted betweenness. Figure 2 shows, no matter what the value of $\alpha$ and $\beta$ are, the SCF equals 0.95 after attacking the Bank of Suzhou with the largest weighted betweenness, which indicate that such attacking will not cause cascading failure. When the Bank of Zhengzhou with the largest weighted betweenness is attacked, the SCF values are all below 0.60 taking different $\alpha$ and $\beta$, which indicates that the attack is easy to cause cascade failure. At the same time, it can be seen from Figure 2 that the SCF reaches its maximum at threshold $\alpha=0.2, \beta 0=0.36$. When $\beta>\beta_{0}$, the SCF not increase any more. When $\beta<\beta_{0}$, the SCF decreases quickly with the $\beta$ decrease. So, attacking the node with the largest weighted betweenness is prone to cascading failure 5 .

\section{Conclusions}

This paper uses LASSO quantile regression technique to select variables, and builds a tail risk connectivity network of China's listed banks from 2007 to 2020. Using cascading failure model in complex networks, the invulnerability and node risk threshold are studied. Here's some results:

Firstly, the newly listed banks mainly play the role of risk bearers in the network. The role of a single bank as an isolator, risk bearer and risk disseminator will change over time.

Secondly, urban commercial banks gradually become influential subjects, from the risk bearer to both risk bearer and risk disseminator.

And thirdly, the research on invulnerability finds that in 2016, 2018, 2019 and 2020, the attacks on Bank of China, China Merchants Bank, China CITIC Bank and Zhengzhou Bank, those have the largest weighted betweenness are easy to cause large-scale cascading failure of the network. If the attacked bank is a risk communicator, it will cause larger cascading failure and reduce invulnerability of the network.

In addition, we find that the magnitude of cascading effect of the network invulnerability is related to the type of attacked bank and its neighbor. If the neighbor bank is the risk bearer, the risk will not be transmitted. If the neighbor bank is a risk disperser, the risk will be further spread and expanded, that is, the size of the cascade also depends on the network cluster structure. We also find that there exist the threshold for $\alpha$ and $\beta$ (e.g., $\alpha=0.2$ and $\beta=0.36$ in the 2020 network), the network's invulnerability reaches the maximum, and the network's ability to resist risks is the strongest.

\section{Acknowledgements}

This research has received financial support from the Fundamental Research Funds for the Central Universities, CUPL (20ZFG79001), the research center for Xi Jinping Thought on Socialism with Chinese Characteristics for a New Era and Social Science Foundation of Beijing (18KDAL043), and the Humanities and Social Science Foundation of the Ministry of Education of China (Project No. 19YJA790046).

\section{References}

[1] Battiston, S., Farmer, J. D., Flache, A., Garlaschelli, D., Haldane, A. G., Heesterbeek, H., Hommes, C., Jaeger, C., May, R., \& Scheffer, M. Complex systems. Complexity theory and financial regulation [J]. Science, 2016, 351 (6275): 818-819.

[2] Billio, M., Getmansky, M., Lo, A. W. Econometric measures of connectedness and systemic risk in the finance and insurance sectors [J]. Journal of Financial Economics, 2012, 104 (3): 535-559.

[3] Jiang, H., Zhang, J. Interconnectedness of banks' tail risk network and its effect on systematic risk: evidence from China's listed banks [J]. Finance \& Trade Economics, 2018, 39 (08): 50-65.

[4] Diebold, F. X., Yilmaz, K. On the network topology of variance decompositions: Measuring the connectedness of financial firms [J]. Journal of Econometrics, 2014, 182 (1): 119-134.

[5] Li, Z., Tu, X., Bu, L. Systemic risks of financial institutions: importance and vulnerability $[\mathrm{J}]$. Journal of Finance and Economics, 2019, 42 (2): 100-112, 152.

[6] Hautsch, N., Schaumburg, J., Schienle, M. Financial network systemic risk contributions [J]. Review of Finance, 2015, 19 (2): 685-738.

[7] Karlhärdle, W., Wang, W., Yu L. TENET Tail-Event driven NETwork risk [J]. Journal of Econometrics, 2016, 192 (2): 499-513.

[8] Nguyen, L. H., Chevapatrakul, T., Yao, K. Investigating tail-risk dependence in the cryptocurrency markets: A LASSO quantile regression approach [J]. Journal of Empirical Finance, 2020, 58 (3): 333-355.

[9] Guo, Y., Li, P., Li, A. Tail risk contagion between international financial markets during COVID-19 pandemic [J]. International Review of Financial Analysis, 2021, 73: 101649.

[10] Javed, F., Sabzevari, H., Virk, N. Tail risk emanating from troubled European banking sectors [J]. Finance Research Letters, 2021: 101952.

[11] Xu, Y. A Study on the Importance of Chinese financial institutions based on tail risk network [J]. Macroeconomics, 2019, 252 (11): 102-111.

[12] Li, Z., Lu, Y., Liu, Q. Tail risk network, systemic risk contribution and China's financial regulation $[\mathrm{J}]$. Economic Perspectives, 2019, (07): 65-79. 